\title{
¿Por qué deben tratarse las aguas residuales?
}

\author{
Ledy Cheyenne de la Cruz Martínez a , Rosa Icela Beltrán Hernández ${ }^{\mathrm{a}}$, Carlos Alexander Lucho Constantino a,*
}

\author{
a Área Académica de Química, Licenciatura en Química, Universidad Autónoma del Estado de Hidalgo. Carretera Pachuca-Tulancingo km. 4.5, Colonia \\ Carboneras. Mineral de la Reforma, Hidalgo. México CP. 42184.
}

\section{Resumen}

Algunas personas piensan que cualquier descarga a un cuerpo de agua es contaminación. Con los sistemas actuales para transportar y conducir las aguas residuales generadas en los hogares y las industrias, sería casi imposible y poco prudente prohibir el vertido de estos desechos a los océanos, ríos y cuencas de aguas subterráneas. De acuerdo a su origen, las aguas residuales se clasifican en domésticas e industriales. También se clasifican en aguas residuales orgánicas e inorgánicas de acuerdo al tipo de residuo presente. Existen residuos poco comunes como los vertidos de los procesos de enfriamiento (que ocasionan cambios térmicos) y residuos radiactivos, principalmente de hospitales, laboratorios de investigación y plantas nucleoeléctricas. El no tratar el agua residual genera efectos negativos a la salud humana y al ambiente. Por lo tanto, se emplean diversas tecnologías para tratar el agua residual conocidas como tratamientos primarios, secundarios y terciarios. En México existen normas oficiales mexicanas que regulan las descargas de agua residual y agua tratada a cuerpos acuáticos, suelos, al sistema de alcantarillado urbano municipal, etcétera. La protección de los recursos hídricos es responsabilidad de todos.

Palabras Clave: contaminación del agua, tratamiento del agua, materia orgánica, enfermedades, normas ambientales.

\section{English Summary}

\section{Why treat wastewater?}

\begin{abstract}
Some people think that any discharge to a body of water is pollution. With current systems for transporting and conducting wastewater generated in homes and industries, it would be almost impossible and unwise to ban the discharge of these wastes into the oceans, rivers and groundwater basins. According to their origin, wastewaters are classified as domestic and industrial. Also, depending on the waste present are classified as organic and inorganic wastewater. There are rare residues such as discharges from cooling processes (leading to thermal changes) and radioactive waste, mainly from hospitals, research laboratories, and nuclear power plants. Not treating wastewater produce adverse effects on human health and the environment. Nowadays various technologies can be used to treat wastewater, known as primary, secondary and tertiary treatments. In Mexico, there are Mexican laws that regulate wastewater and treated water discharges to a water bodies, soils, and municipal urban sewer systems, etcetera. Water resource protection is everyone's responsibility.
\end{abstract}

Keywords: wastewater pollution, wastewater treatment, organic matter, disease, environmental laws.

\footnotetext{
* Autor en correspondencia.

Correo electrónico: luchouaeh@ gmail.com (Carlos A. Lucho Constantino)
} 


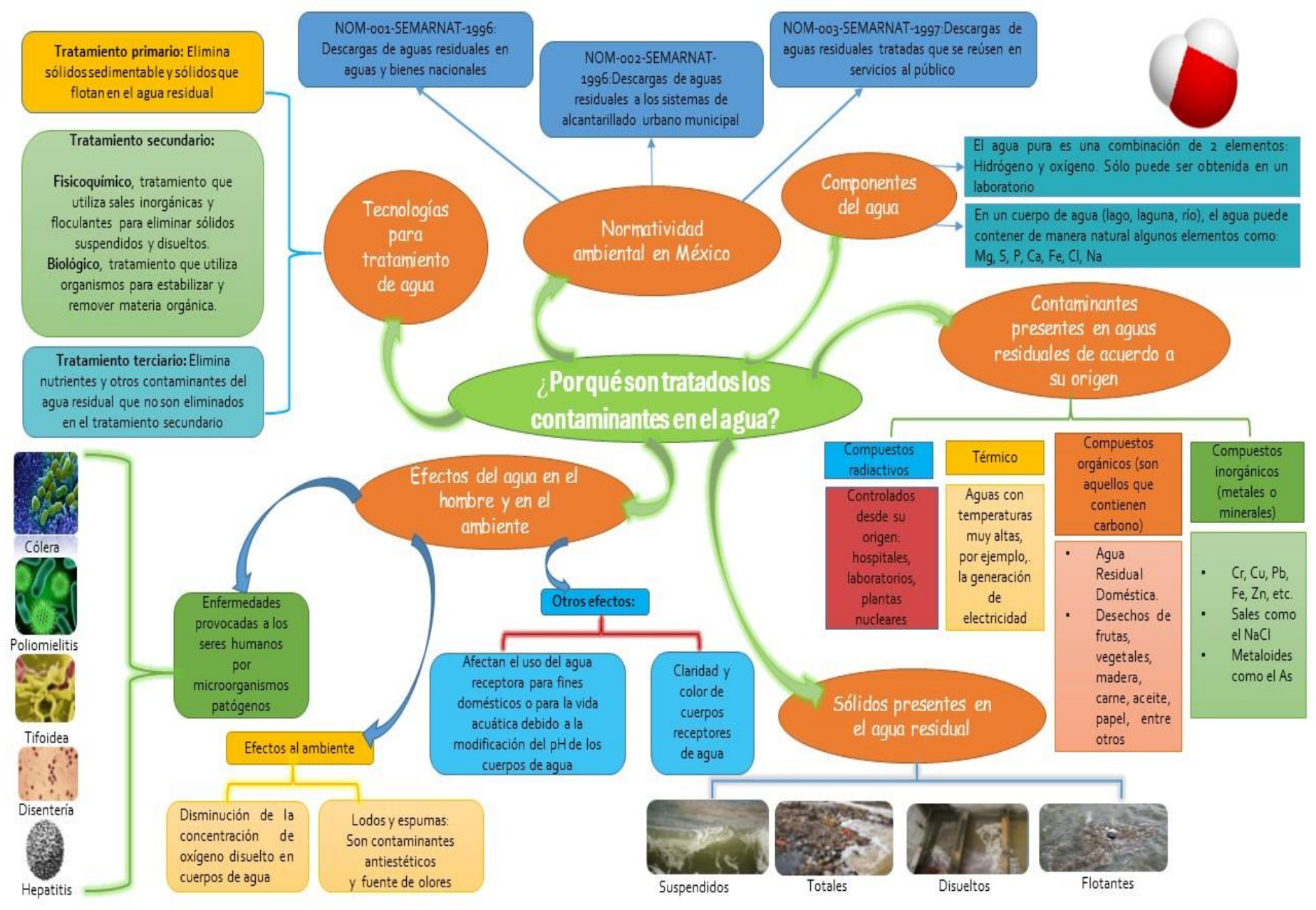

\section{Agradecimientos}

Agradecemos a los revisores anónimos que ayudaron con sus sugerencias y comentarios a mejorar este documento.

\section{Referencias}

Diario Oficial de la Federación (1997). Norma Oficial Mexicana (NOM)001-SEMARNAT-1996. Que establece los límites máximos permisibles de contaminantes en las descargas de aguas residuales en aguas y bienes nacionales.

Diario Oficial de la Federación (1998a). Norma Oficial Mexicana (NOM)002-SEMARNAT-1996. Que establece los límites máximos permisibles de contaminantes en las descargas de aguas residuales a los sistemas de alcantarillado urbano o municipal.

Diario Oficial de la Federación (1998b). Norma Oficial Mexicana (NOM)003-SEMARNAT-1996. Que establece los límites máximos permisibles de contaminantes para las aguas residuales tratadas que se reusen en servicios al público.

Environmental Protection Agency (USEPA). Why treat wastes?. Operation of wastewater treatment plants Volume 1. Cuarta edición, Universidad de California. 1998. pp. 12-25. 